\title{
Parathyroid Gland Adenoma
}

National Cancer Institute

\section{Source}

National Cancer Institute. Parathyroid Gland Adenoma. NCI Thesaurus. Code C3916.

A neoplasm arising from the parenchymal cells of the parathyroid glands. In the vast majority of cases, the tumor involves a single parathyroid gland. It is associated with the symptoms of primary hyperparathyroidism, resulting from the excessive production of parathyroid hormone. It is usually surrounded by a well-defined capsule. Capsular invasion, vascular invasion, and perineural invasion are absent. Overall cure rates are excellent following excision of the abnormal gland(s). 